\title{
Pengaruh Walking Tandem Exercise Pada Lansia Sehat di Panti Lanjut Usia Harapan Kita Palembang
}

\author{
Yudiansyah* \\ *Prodi DIII Fisioterapi, Fakultas Ilmu Kesehatan IKesT Muhammadiyah Palembang \\ Email korespondensi: yudiansyah.yudiansyah@gmail.com
}

\begin{abstract}
ABSTRAK
Pendahuluan: Proses penuaan terjadi secara alami diikuti dengan adanya penurunan kondisi fisik, psikologi maupun social diantaranya adalah penurunan kekuatan otot, dan penurunan fungsi otak sehingga timbul banyak permasalahan pada lansia dalam melakukan kegiatan sehari-harinya. Metode: Pre-post desain pada 34 lansia dan dilakukan screening dengan MMSE, lansia dengan nilai MMSE >24 point diberikan Walking Tandem Exercise (WTE) sebanyak 3 kali dengan istirahat 1 menit diantara tiap sesi dilakukan 2 kali seminggu selama 4 minggu. Hasil: Uji beda nilai pre-post test diperoleh hasil $p=0,012(p<0,05)$. Kesimpulan: Hasil penelitian ini menunjukkan bahwa ada perbedaan yang bermakna pada nilai indeks katz sebelum dan sesudah diberikan WTE.
\end{abstract}

Kata Kunci: Walking Tandem Exercise, Indeks Katz, Lansia

\section{The Effect of Walking Tandem Exercise on The Healthy Elderly Population in Panti Lanjut Usia Harapan Kita Palembang}

\begin{abstract}
Introduction: The aging process is occurs naturally, followed by a decreased in physical, psychological and social conditions, including a decrease in muscle strength, and a decrease in brain function, resulting in many problems for the elderly in carrying out their daily activities. Method: Pre-post design in 34 healthy elderly and screening with MMSE, healthy elderly with MMSE value $>24$ points were given Walking Tandem Exercise (WTE) 3 times with a rest of 1 minute between each session performed 2 times a week for 4 weeks. Results: The prepost test value difference test resulted in $p=0.012(p<0.05)$. Conclussion: The results of this study indicate that there is a significant difference in the Katz index value before and after being given.
\end{abstract}

Keywords: Walking Tandem Exercise, Index Katz, Healthy Elderly

\section{PENDAHULUAN}

Lanjut usia (lansia) adalah kelompok penduduk yang berusia 60 tahun ke atas. Secara biologis lanjut usia ialah orang yang mengalami proses penuaan, yang ditandai dengan penurunan fungsi organ-organ, termasuk tulang dan otot. Penurunan massa tulang dan otot akan menyebabkan penurunan kemampuan seseorang untuk menjaga keseimbangan yang dapat menyebabkan seseorang bisa terjatuh dan terganggu dalam melakukan kegiatan sehari-hari (Susilo,2013).

Usia lanjut yang dialami oleh lansia akan menyebabkan lansia mengalami perubahan. Secara garis besar perubahan yang terjadi pada lansia diantaranya, perubahan fisik, perubahan kognitif, perubahan emosional, perubahan psikososial. Sistem indra, sistem muskuloskeletal. Perubahan fisiologis pada sistem muskuloskeletal diantaranya akan mempengaruhi penurunan kekuatan otot, penurunan 
fleksibilitas, penurunan elastisitas dan penurunan kekuatan luas gerak sendi yang hal ini dapat menimbulkan risiko jatuh pada lansia (Naftali,2017).

Perubahan penuaan dan masalah kesehatan sering menunjukkan penurunan status fungsional pada lansia. Salah satu cara terbaik untuk mengevaluasi status kesehatan lansia adalah melalui penilaian fungsional yang menyediakan data objektif yang dapat menunjukkan penurunan masa depan atau peningkatan status kesehatan (Wallace dan Shelkey, 2008).

Kemandirian adalah kemampuan untuk memenuhi kebutuhan seseorang, adalah tujuan paling penting pada sebagian besar lansia tanpa melihat status kesehatannya. Kemandirian memberikan mereka rasa kehormatan, kebanggaan dan berfungsinya diri sehingga tidak menjadi beban bagi orang lain (Wiraguna, 2014). Sedangkan menurut Poerwadi (2001) mandiri adalah dimana seseorang dapat mengurusi dirinya sendiri, ini berarti bahwa jika seseorang sudah menyatakan dirinya siap mandiri berarti dirinya ingin sesedikit mungkin minta pertolongan atau ketergantungan kepada orang lain.

Solusi yang ditawarkan al-Qur'an untuk mengatasi segala permasalahan yang dihadapi oleh para usia lanjut adalah sebagaimana yang tersirat dalam Q.S. Al-Hijr [15] ayat 54 agar setiap orang yang telah menginjak usia lansia, hendaklah tetap semangat dalam menjalani hidup, dan jangan mudah putus asa. Adapun dalam hal anjuran untuk senantiasa memperhatikan para lansia dianjurkan melalui perintah pada Q.S. Isra' ayat 23. Sebagaimana manusia yang arif dan bijaksana tentunya kita tidak boleh lalai dengan urusan duniawi semata, terlebih bagi mereka yang sudah masuk fase lanjut usia, karena banyak yang harus kita siapkan baik secara dhohir maupun batin. Sebagaimana firman Allah dalam Q.S. Yasin [36] ayat: 68 yang artinya
"Dan barang siapa yang kami panjangkan umurnya niscaya kami kembalikan dia kepada kejadianya, maka apakah mereka tidak memikirkannya".

Metode penanganan Fisioterapi yang dapat mengurangi faktor risiko jatuh pada lansia adalah dengan menggunakan latihan jalan Tandem (Nugraha,2014). Jalan Tandem (Tandem stance) merupakan suatu latihan yang dilakukan dengan cara berjalan dalam satu garis lurus dan posisi tumit menyentuh jari kaki yang lainnya sejauh 3-6 meter. Latihan ini berguna untuk memperbaiki postural dan menaikkan konsentrasi lansia saat berjalan (Nugrahani,2014).

Berdasarkan hasil penelitian oleh Made (2017) didapatkan hasil bahwa jalan tandem dapat mengurangi faktor risiko jatuh pada lansia setelah diberikan latihan selama 5 minggu secara rutin (Made dkk, 2018). Dengan demikian diharapkan kemampuan lansia dalam melakukan kegiatan sehari-harinya akan meningkat sehingga dapat melakukan aktifitas sehari-hari secara mandiri.

\section{BAHAN DAN METODE}

Penelitian ini adalah quasi eksperiment dengan desain penelitian pre - post test yang bertujuan untuk mengetahui perubahan tingkat kemandirian lansia setelah diberikan latihan walking tandem exercise. Teknik pengambilan sampel yang dilakukan pada penelitian ini adalah purposive sampling dengan kriteria Inklusi: 1) lansia tanpa gangguan pendengaran dan penglihatan; 2) lansia yang memiliki nilai MMSE diatas 24 poin; 3) lansia tanpa komplikasi penyakit apapun; 4) lansia tanpa ada gangguan musculoskeletal; dan 5) Lansia yang mampu berkomunikasi.

Penelitian ini dilakukan dua kali seminggu selama empat minggu. Fisioterapis meminta lansia untuk berdiri tegak dan berjalan perlahan kedepan dengan ibu jari kaki satu menyentuh tumit kaki sisi lainnya sejauh 3 meter. Pasien di minta untuk melakukan hal 
yang sama sebanyak tiga kali dengan jedah waktu satu menit diantara sesi nya. Hal ini dilakukan untuk mencegah lansia mengalami kelelahan. Rata-rata nilai akan dianalisa dengan uji pairedsamples t test.

\section{HASIL}

Karakteristik responden berdasarkan jenis kelamin dapat dilihat pada tabel di bawah ini :

Tabel 1. Karekteristik Responden Berdasarkan Jenis Kelamin Jenis Frekuensi $\%$ Kelamin

\begin{tabular}{lcc}
\hline Laki-laki & 16 & 46 \\
Perempuan & 18 & 54 \\
\hline Total & 34 & 100 \\
\hline
\end{tabular}

Berdasarkan tabel 1 diatas responden yang paling banyak mengikuti penelitian ini adalah responden yang berjenis kelamin perempuan.

Karekteristik responden berdasarkan usia dapat dilihat dari tabel dibawah ini:

\begin{tabular}{lcc}
\multicolumn{3}{c}{ Tabel 2. Karakteristik Responden } \\
Berdasarkan Usia \\
\hline Jenis & Frekuensi & $\%$ \\
Kelamin & & \\
\hline $60-65$ & 22 & 63 \\
$66-70$ & 9 & 26 \\
$71-75$ & 3 & 11 \\
\hline Total & 34 & 100 \\
\hline
\end{tabular}

Keterangan yang dapat kita ketahui dari tabel 2 diatas adalah usia responden pada penelitian ini paling banyak adalah pada rentang usia 60 - 65 tahun yaitu sebanyak 22 responden

Hasil analisis pada penelitian ini diketahui bahwa $p$-value $0.000(p<0.05)$ dari data tersebut diketahui nilai Indeks Katz mengalami perubahan yang signifikan (berarti). Berdasarkan statistika deskriptif tersebut terbukti post test lebih tinggi. Maka, dapat disimpulkan bahwa Walking Tandem Exercise dapat meningkatkan tingkat kemandirian lansia. Hasil uji statistic dapat dilihat pada table di bawah ini.
Tabel 3. Indeks Katz Pre dan Post Walking Tandem Exercise

\begin{tabular}{lllll}
\hline Indeks Katz & n & Mean & SD & Sig. \\
\hline $\begin{array}{l}\text { Pre } \\
\text { Intervensi }\end{array}$ & & & & \\
$\begin{array}{l}\text { Walking } \\
\text { Tandem } \\
\text { Exercise }\end{array}$ & 34 & 8.22 & 4.221 & \\
\hline $\begin{array}{l}\text { Post } \\
\text { Intervensi }\end{array}$ & & & & \\
$\begin{array}{l}\text { Walking } \\
\text { Tandem } \\
\text { Exercise }\end{array}$ & 34 & 18.46 & 5.153 \\
\hline
\end{tabular}

\section{PEMBAHASAN}

Pada penelitian ini berjumlah 34 subyek penelitian dengan jenis kelamin laki-laki dan perempuan memiliki rentang usia antara 60-75. Penyebab turunnya tingkat kemandirian pada lansia diantaranya gangguan kognitif, kelemahan otot, postur yang jelek, gangguan penglihatan, gangguan keseimbangan dan pola jalan yang tidak normal. Semua faktor tersebut merupakan faktor utama terjadinya jatuh. Dilaporkan pada penelitian lain diketahui $51 \%$ orang dengan gangguan keseimbangan umur 65-74 tahun (Utomo, 2009). Usia berhubungan dengan keseimbangan karena terjadinya perubahan fungsi tubuh yang menyebabkan keseimbangan menurun sehingga tingkat kemandirian pada lansia pun menurun.

Walking tandem exercise merupakan suatu latihan yang bertujuan meningkatkan fungsi dari pengontrol keseimbangan tubuh yaitu sistem informasi sensorik, central processing dan efektor untuk bisa beradaptasi dengan perubahan lingkungan. Hal ini sejalan dengan penelitian yang dilakukan Talkowski (2008) yang mengatakan ketika melakukan latihan jalan tandem, lansia dilatih secara visual dengan melihat kearah depan agar memperluas arah pandangan untuk dapat berjalan lurus (Ma de, 2018). Sehingga hal tersebut dapat menimbulkan rangsangan pada system vestibular.

Hasil uji hipotesa I menggunakan paired-samples $t$ test dengan jumlah 
responden 34 dengan pemberian latihan tandem gait exercise terhadap keseimbangan pada lansia. Diperoleh nilai $p$-value $0.000(p<0.05)$. Sehingga dapat disimpulkan bahwa pemberian walking tandem exercise berpengaruh terhadap peningkatan kemandirian lansia. Pemberian tandem gait exercise tidak hanya mampu meningkatkan keseimbangan, selain itu walking tandem exercise merupakan salah satu latihan yang bertujuan untuk melatih sikap atau posisi tubuh, mengontrol keseimbangan, koordinasi, dan gerakan tubuh yang sangat baik bagi para lansia sehingga dapat meningkatkan kemandirian lansia dalam beraktifitas sehari-hari (Nugrahani, 2014).

\section{SIMPULAN DAN SARAN Simpulan}

Penelitian ini membuktikan bahwa walking tandem exercise dapat meningkatkan kemandirian lansia. Sehingga exercise ini dapat dilakukan oleh para lansia untuk meningkatkan kemandiriannya dalam toileting, berpakaian, ambulasi, makan dan melakukan aktivitas keseharian lainnya.

\section{Saran}

Mengingat kemandirian pada lansia merupakan suatu masalah yang terjadi pada sekian ratus juta lansia di dunia, maka hendaknya dilakukan penanganan terhadap pasien sedini mungkin agar dapat menjalankan aktivitas sehariharinya seoptimal mungkin.

\section{PENDANAAN}

Penelitian ini di danai dari hibah STIKes MP tahun anggaran 2019/2020.

\section{KONFLIK KEPENTINGAN}

Pada penelitian ini tidak terdapat konflik kepentingan apapun.

\section{UCAPAN TERIMA KASIH}

Penulis mengucapkan terimakasih kepada Rektor IKesT MP atas hibah dana yang diberikan sehingga penelitian ini dapat terlaksana. Penulis juga mengucapkan banyak terimakasih kepada pimpinan Panti Lanjut Usia Harapan Kita Palembang, dan penduduk panti atas kebaikannya dan serta kooperatif selama penelitian ini berlangsung hingga selesai.

\section{KEPUSTAKAAN}

Algra, M. H Corlberg, E, V. (2008). Postural Control : A Key Issuein Devlomental Disorder. Mac Keith Press. Lander.

Azizah, L, M. (2011). Keperawatan Lanjut Usia. Yogyakarta. Graha IImu.

CallisayaML., Blizzard L., McGinley JL., Srikanth VK. 2012. Risk of Falls in Older People During Fast-Walking. Gait and Posture. Australia.

Irfan M, 2010. Fisioterapi Bagi Insan Stroke Edisi Pertama. Graha IImu. Yogyakarta.

Made dkk, (2018). Latihan Jalan Tandem Lebih Meningkatkan Keseimbangan Lansia Dari Pada Latihan Balance Strategy. Sport And Fitness. Volume 6, No. 1.

Mansfield PA dan Neumann DA. 2009. Essentials of Kinesiology for the Physical Therapist Assistant. USA: Elsevier.

Nugrahani, P, N. (Oktober 2014). Latihan Jalan Tandem Lebih Baik Daripada Latihan Dengan Menggunakan Swiss Ball Terhadap Peningkatan Keseimbangan Untuk Mengurangi Risiko Jatuh Pada Lanjut Usia (Lansia). Jurnal Fisioterapi. Volume 14. Nomor 2.

Sumway-Cook, A. Dan M.M. Wollacott (2012). Motor Control: Translating Research into Clinical Practice. Wolters Kluwer, Lippincott Williams \& Wilknins.

Made dkk, (2018). Latihan Jalan Tandem Lebih Meningkatkan Keseimbangan Lansia Dari Pada Latihan Balance Strategy. Sport And Fitness. Volume 6, No. 1. 
Naftali, R, A., Yulias, Y, R., Anwar, A, M. (2017). Kesehatan Spiritual dan konsep lansia dalam menghadapa i kematian. Http://jurnal.Ugm.Ac.Id /Buletinpsikologi. Volume 25. Nomor 2 halaman 124-135.

Nugrahani, P, N. (Oktober 2014). Latihan Jalan Tandem Lebih Baik Daripada Latihan Dengan Menggunakan Swiss Ball Terhadap Peningkatan Keseimbangan Untuk Mengurangi Risiko Jatuh Pada Lanjut Usia (Lansia). Jurnal Fisioterapi. Volume 14. Nomor 2.

Tamher, S. \& Noorkasiani. (2009). Kesehatan Usia Lanjut Dengan Pendekatan Asuhan Keperawatan. Jakarta : Selemba Medika.
Utomo, Budi \& Takarini, Nawangsari. (2009). Uji validasi Time up and go test (TUGT) sebagai alat ukur keseimbangan pada lansia. Jurnal fisioterapi Vol.9. No 2, Oktober 2009.

Valentin, L (2016). Perbedaan Pemebrian Latihan Jalan Tanden dan One Lage Stance Untuk Meningkatkan Keseimbangan Dinamis Pada Lansia. Denpasar. Universitas Udaya.

Yuliani, S. (2014). Latihan Kombinasi Corestability Exercise dan Ankle Strategy Exercise Tidak Lebih Meningkatkan Dari Corestability Exercise Untuk Keseimbangan Statis. Yogyakarta. Universitas Ais 